\title{
Public Space Engagement and ICT Usage by University Students: An Exploratory Study in Three Countries
}

\author{
Paschalis Arvanitidis ${ }^{1(\bowtie)}$ (D), Therese Kenna² (D), \\ and Gabriela Maksymiuk ${ }^{3}$ (D) \\ ${ }^{1}$ University of Thessaly, Volos, Greece \\ parvanit@uth.gr \\ 2 University College Cork, Cork, Ireland \\ t.kenna@ucc.ie \\ 3 Warsaw University of Life Sciences, Warsaw, Poland \\ gabriela_maksymiuk@sggw.pl
}

\begin{abstract}
The new mobile information and communications technologies expand human connectivity to reconfigure public spatialities and to give rise to novel needs for, and practices of, public space usage. The research in this chapter focuses on university students to explore how they perceive and use the public space of university campuses and how they use personal information and communications technologies in it. This allows for an identification of emerging patterns and practices of university public space usage, along with preferable characteristics, designs and ways of management. Data are collected from three case studies, the University College Cork in Cork (Ireland), the University of Thessaly in Volos (Greece), and the Warsaw University of Life Sciences in Warsaw (Poland), enabling us to spot similarities and differences in the above trends, that would be attributed to culture and local conditions and lifestyles.
\end{abstract}

Keywords: University public space ·

Information and communications technologies - University students ·

Cross-cultural analysis

\section{Introduction}

One dominant and momentous trend is emerging as a defining hallmark of the contemporary era: the rapid global diffusion of personal information and communications technologies (ICTs), including mobile and smart phones, personal laptops and tablets devices (see Graham 2002). This rapid diffusion and uptake of personal ICTs presents a new societal challenge for cities of increasing diversity and inequality as social life in the city becomes increasing (yet perhaps unevenly) mediated by personal digital devices. The introduction of mobile personal digital technologies - such as mobile phones and personal laptops and tablets - is transforming the ways in which people use and engage with urban public space, as well as encounter others within those spaces 
and engage in social interactions and activities. While it is widely held that the introduction of ICTs has resulted in significant changes to the organisation of cities, public spaces and everyday social life (Graham 2002; Aurigi and de Cindio 2008), it remains that there is little research into the exact nature of the socio-cultural transformation resulting from personal ICT usage in the city and urban public spaces.

The current chapter draws on a wider research project undertaken by the research team aiming to investigate how university students engage with personal ICTs and urban public spaces, especially within a university campus, or what we call, University Public Spaces ${ }^{1}$ (UPS), as a way of engaging with critical debates concerning young people's social and digital engagement and encounter. This was performed through a comparative study in three different geographical regions of Europe (North, South, East) to ascertain differences based on geographical and cultural context, via the development of new digital social science research methods (online questionnaires). More specifically, the chapter is guided by the following objectives:

1. To explore the perceptions and attitudes of university students towards UPS. This objective included questions such as: What types of UPS do students use and engage with the most? How do university students use UPS? What features or attributes of the UPS do they value the most? Are they willing to participate in UPS management and maintenance?

2. To explore perceptions, attitudes and patterns of ICT usage among university students. This objective involved a series of sub-questions, such as: How intensively do university students use ICTs? What kind of devices and services are used? What activities do university students engage in whilst using ICTs? How they make use of ICTs when they are in UPS?

For the needs of the chapter, we reflect on preliminary analysis of the data to offer some initial observations regarding university student use of ICTs and UPS in universities at three European cities: Cork (Ireland); Volos (Greece); and Warsaw (Poland). Following this introduction, the chapter moves to explore some of the key literature in this field of research relating to ICT usages in urban public spaces, as well as on university campuses. This is followed then by a discussion of our research methodology, an introduction to our case studies, and preliminary analysis of the data. The chapter concludes with a discussion of the key findings.

\section{New ICTs and the Usage of UPS}

The proliferation of personal ICT devices has led scholars (predominantly in communication studies, as well as urban studies) to speculate about their exclusiveness, their perceived contributions to increasing privatisation and privatism in urban society

\footnotetext{
${ }^{1}$ UPS is a kind of semi-public space, in the sense that it is owned or controlled by a public institution and it is partially, but not entirely, visible to and open to the use of the general public. Such spaces include, for example, university gardens, green spaces, walkways and entrance ways to university buildings (outdoor spaces), as well as indoor spaces such as student centers, refectories, or common areas within university buildings like the library.
} 
(i.e. their role in widening the gap between the public and private realms), their contribution to the reduction of encounters with 'others' or the stranger and reduced chance encounters (Hampton et al. 2010; Hampton and Gupta 2008; Hatuka and Toch 2014; Leyshon et al. 2013). For example, Hampton et al. (2010) studied people's use of Wi-Fi on personal mobile devices in public and semi-public spaces in a number of North American cities. This work found that although the availability of Wi-Fi in public spaces increased peoples use of such spaces, they were found not to be active participants in the social activities of the public spaces (i.e. they were 'silent spectators'). The research concluded that the use of wireless internet on personal mobile digital devices in these spaces afforded a public privatism whereby people engaged in private personal activities and their private social networks whilst in public space, thus they were not active participants in public space. Further, the work of Leyshon et al. (2013) examined how young people locate themselves in the city through their use of GPSenabled mobile phones. This research was partly concerned with the role of GPSenabled mobile phones in young people's way-finding and exploration through the city. While the study found that the young people were less like to 'get lost' in the city and had greater confidence in exploring new places as a result of their GPS-enabled mobile phones, they also found that the mobile devices proved a distraction from their surroundings in that they were less inclined to observe or engage with the surrounding urban environment. Findings, such as those from the aforementioned studies, create concerns for the diminishing value of public space in a traditional sense, for the declining significance of the city and urban spaces in the digital era, and for the potential of ICTs to generate and increase social inequalities, as well as reduce opportunities for encountering 'others' in the city (Valentine 2008). It is generally these themes that the undertaken research sought to explore in relation to university students and their uses of public spaces on the university campus.

Boren (2014) noted that there were now more mobile devices globally than people, making the mobile phone one of the fastest diffusing technologies in history with over seven billion mobile devices in global circulation. According to Leyshon et al. (2013), young people own many of these mobile devices and, as such, there are ongoing investigations into how new technologies are 'changing young people's behaviour, social relationships, attention spans, time expenditure and privacy' (pp. 587-88). Given that young people are thought to be one of the most 'tech-savvy' segments of society with almost constant connectivity to digital devices, as well as constituting a significant target market for tech company products and innovations, we focussed our research on young people, mostly notable university students (predominantly aged 18-25).

There have been very few studies of how students actually use, perceive and evaluate campus green spaces (Speake et al. 2013), and furthermore there have been no research of how students use ICTs within university public spaces. Among topics discussed in previous studies related to campuses, there are: campuses studied as public spaces (Gumprecht 2007), campus green spaces and their positive influence on quality of life (McFarland et al. 2008) and campus as a tool for promotion of university (Griffith 1994). In his research, Gumprecht (2007), for instance, outlines that attractive and lively campuses enhance students' experience of academic life, create memories and build loyalty among fellow students. Griffith (1994), in turn, reports that a choice of university often depends on the prospective student's perception of the campus. 
The studies of Speake et al. (2013) explored students' perceptions and use of university campus green spaces - the case study of Liverpool Hope University. Their findings reveal that the vast majority of students both use and is pleased about green spaces, and believe there are important for the image of the university and make an essential component of the campus environment. Besides, the authors of this study underline that university campuses need various types of green spaces in order to satisfy the multifarious needs of students. However, they haven't considered applying of ICT as example of such solutions, yet. In terms of social functions, the campus was described by surveyed students as place for "meeting people", "chatting with friends", "waiting for classes" or "simply for socialising" (Speake et al. 2013: 24). Furthermore, among most popular activities undertaken by students in UPS, the authors of quoted paper list: relaxation, eating or drinking, studying or sport.

\section{Exploring ICT and UPS Usage in Three Case Studies}

\subsection{Research Concept and Methodology}

This section discusses how university students perceive and report to use UPS and ICTs in three case studies across Europe: The University College Cork in Cork, Ireland, the University of Thessaly in Volos, Greece, and the Warsaw University of Life Sciences in Warsaw, Poland. Data were collected through an online questionnaire survey that explored students' views, attitudes, stances and behaviours towards UPS and ICTs, examining a number of issues, such as: the qualities and facilities available in UPS, the ways and intensity of UPS use, the social interactions taking place, the student's willingness to contribute to UPS management, the kind of ICT devices and services used, the intensity of their use and the activities students engage in through ICTs.

The questionnaire used consists of seven parts containing 56 questions of all kinds: measurement, dichotomous, ordinal, as well as Likert-type ones scaled from 1 (denoting strong disagreement, negative opinion, etc.) to 5 (denoting strong agreement, positive opinion, etc.). In particular, the first part of the questionnaire informs the participants on the purpose of the research and ensures the anonymity of participation. The second part records views regarding the condition of the UPS they use most (qualities, facilities, etc.) and the way these are used (intensity, activities, social interactions, etc.). The third and fourth parts assess respectively how students use ICTs generally in their life and in particular when they are in UPS (devises, services, ways of use, etc.). Part five examines aspects of UPS management and the willingness of students to get involved in this. The sixth part examines the social life of the students and their stances towards other people and institutions. Finally, the last part gathers socio-demographic information, such as gender, age, nationality, discipline of study, and economic status.

The survey took place in the second quarter of 2017. Questionnaires were distributed electronically by the research team, via Google forms, to university students. Apart from the initial invitation to participate in the research, students were notified two more times (through emails) to complete the developed questionnaire. This increased substantially the response rate and the quality of the survey. Responses were then put together, validated, coded and analysed to generate a number of statistics illustrating the respondents' answers on the issues raised. 


\subsection{Description of the Cases}

University College Cork (UCC) is the second largest tertiary education institution in the Republic of Ireland and the largest higher education institution in Cork city. UCC has approximately 20,000 full-time students, which includes 14,000 undergraduate students and 4,000 Masters and PhD students (www.ucc.ie, 2017). Physically, UCC is a large campus to the western edge of the city centre of Cork. The main campus boasts a number of UPS, such as the main student centre, the amphitheatre, president's garden and various boulevards and spaces within buildings (Fig. 1). UCC recently introduced high-quality free Wi-Fi throughout the University Campus, via EduRoam, so students, visitors and staff have access to high-quality internet at all times.

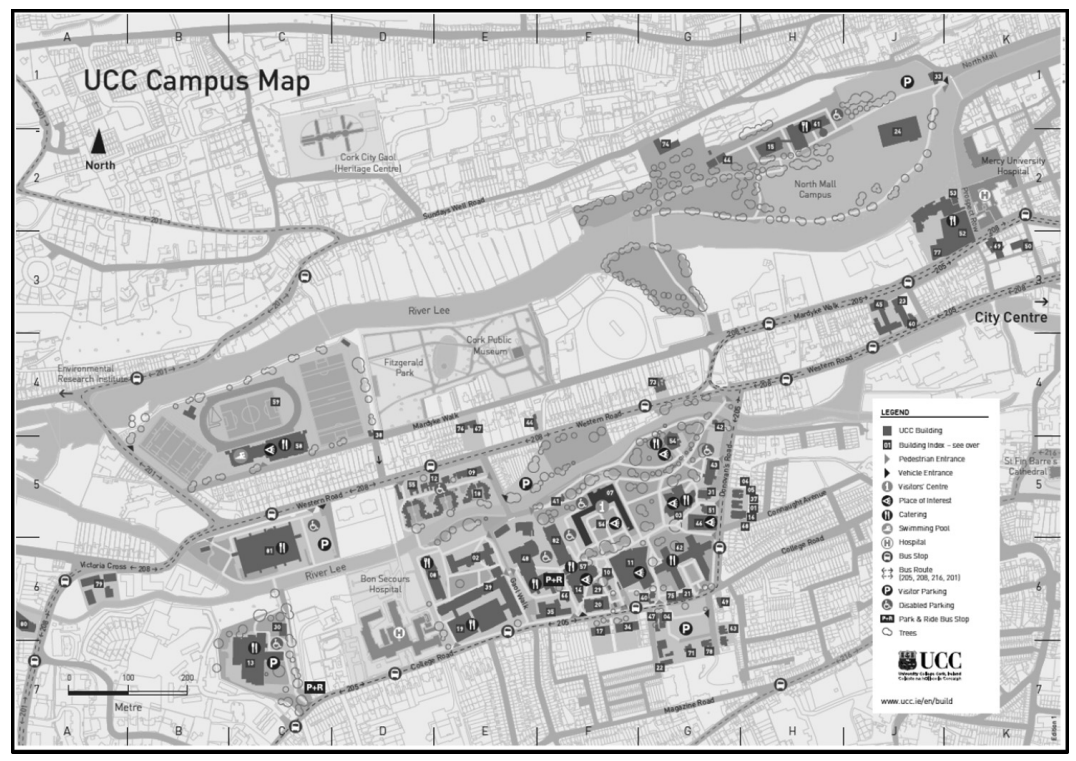

Fig. 1. Map of the UCC campus (Source: https://www.ucc.ie/en/media/academic/languagecen tre/UCC_campus_map_Edition1_2010-new.pdf; Accessed on 1st July, 2017)

The University of Thessaly (UTH) is one of the new public universities in Greece having been founded in 1984. It is comprised of eighteen Departments organized in six Schools. UTH has more than 10,000 undergraduate students, 1,500 postgraduate and 1,000 PhDs (www.uth.gr, 2017). The University is located in central Greece (in Thessaly region), operating campuses in five cities: Volos, Larisa, Trikala, Karditsa and Lamia. The administration and most of the Departments (twelve of them) are deployed in Volos, and UPS is scattered all over the city (Fig. 2). UTH provides high-quality free Wi-Fi throughout its campuses and buildings, so all academic community and visitors have access to high-quality internet at all times. 


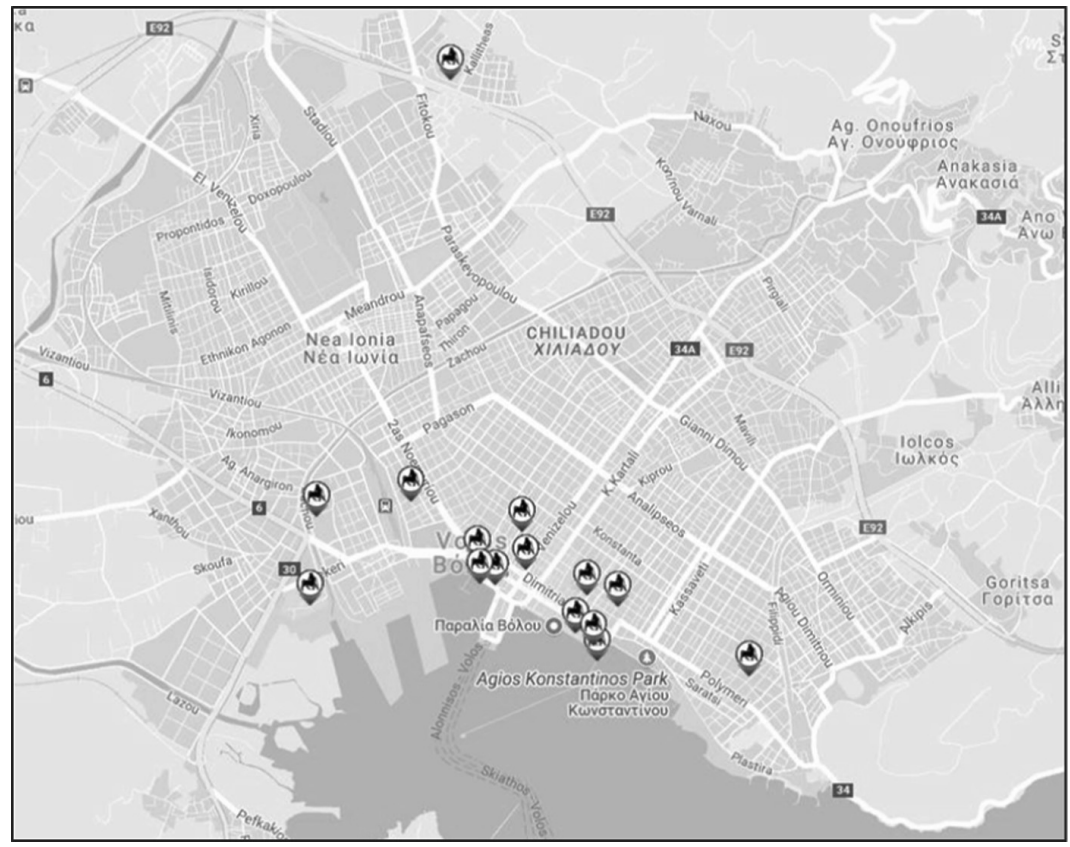

Fig. 2. Map of the UTH locations in Volos city (Source: own construction)

Warsaw University of Life Sciences (WULS) is the oldest and the largest life sciences university in Poland and the third largest higher education institution in Warsaw (in terms of number of students). WULS has approximately 25,000 full-time students and 1,200 academics (www.sggw.pl, 2017). The university campus is located in the southern part of Warsaw and it covers an area over 70 hectares, which makes it the biggest university campus in Warsaw. The campus is divided into 2 parts - the Old Campus, which is a historical park with an arboretum and Neo-Renaissance architecture and the New Campus, where new university buildings, students' dormitories and sport centre are located. The WULS campus consists of a wide array of public spaces and recreational facilities, such as an old park and arboretum, vast lawn areas for picnics, a grill zone and faulty courtyards (Fig. 3). WULS very recently introduced a free Wi-Fi in selected parts of the campus and buildings provided by EduRoam, and in the near future the whole campus area is planned to be covered by a high-quality internet at all times. 


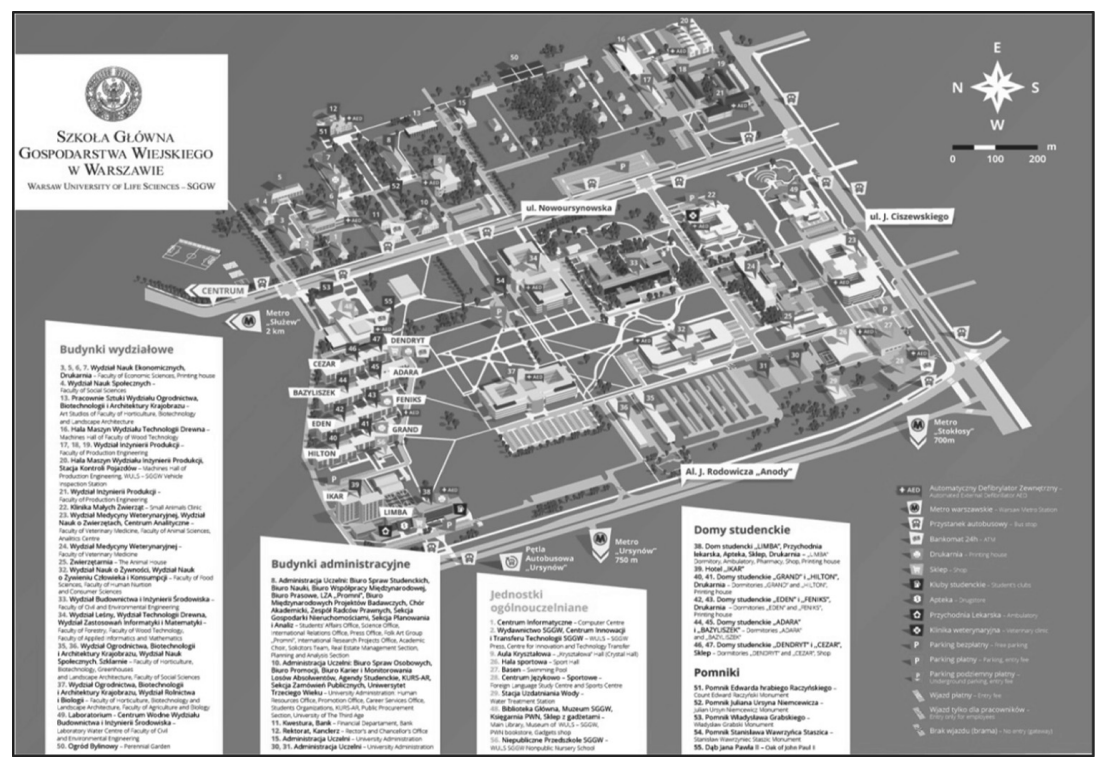

Fig. 3. Map of the WULS campus (Source: http://www.sggw.pl/en/contact_/sggw-campus\#pretty Photo; Accessed on July 2nd, 2017)

\subsection{Composition of Respondents}

A total of 172 responses were received, of which $168(97.7 \%)$ were valid. Of those, about $41.4 \%$ were from students of THU (Greece), $32.0 \%$ of WULS (Poland) and $26.6 \%$ of UCC (Ireland) (see Fig. 4). The nationality of the respondents was mainly Greek, Polish and Irish, but there were few originating from other countries too (see Fig. 5). Their gender composition was about $68.9 \%$ female and $26.9 \%$ male, whereas a $4.2 \%$ of the students selected the option "prefer not to say" (see Fig. 6). The average age of our sample was about 22.7 years, with the youngest being 19 years old and the oldest 47. Their chosen subjects of study were various, though the majority were students of economics, landscape architecture, geography, spatial economy and arts (see Fig. 7). The respondents' economic conditions were, on average, about moderate to low (Fig. 8). 


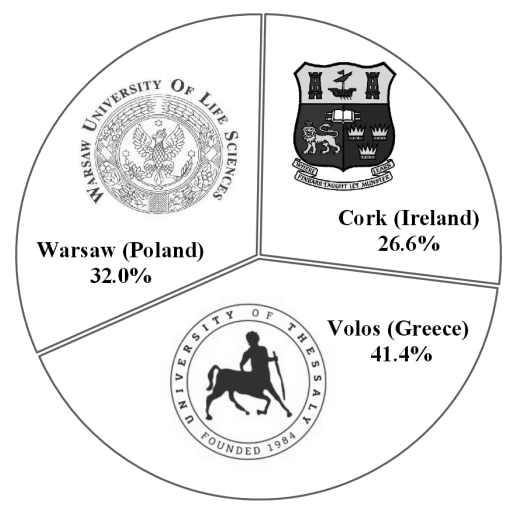

Fig. 4. Origin country of respondents

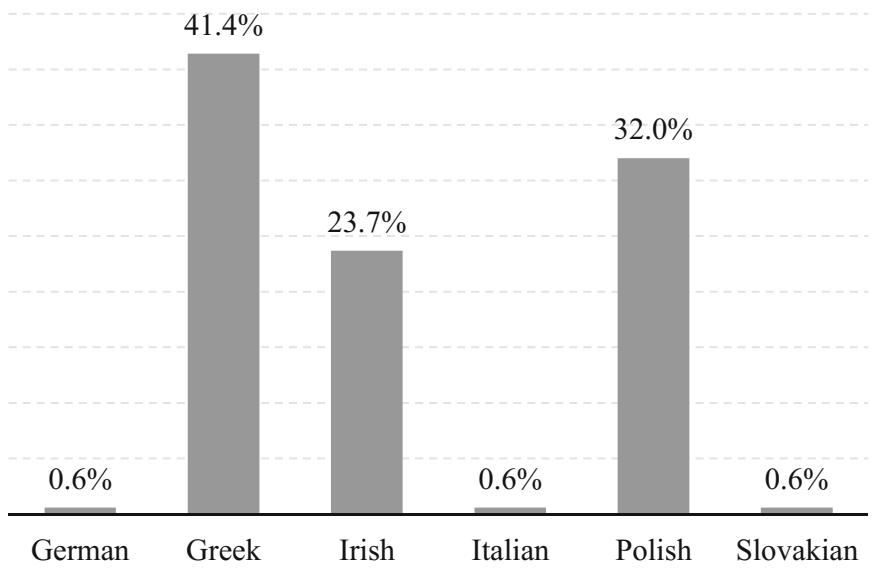

Fig. 5. Nationality of respondents

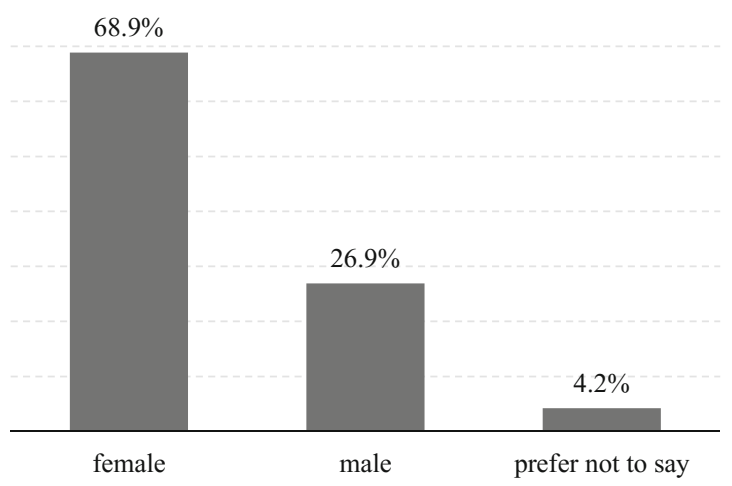

Fig. 6. Gender of respondents 


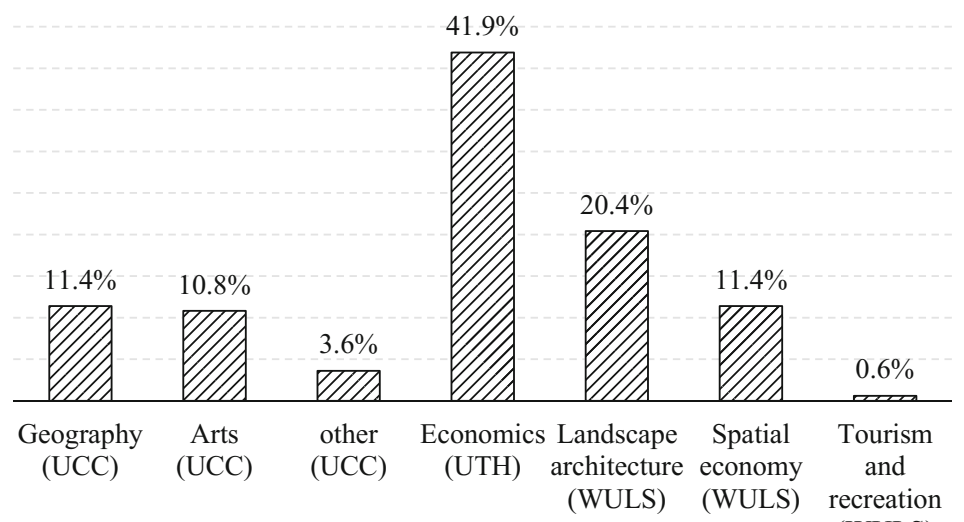

(WULS)

Fig. 7. Field of study of respondents (major)

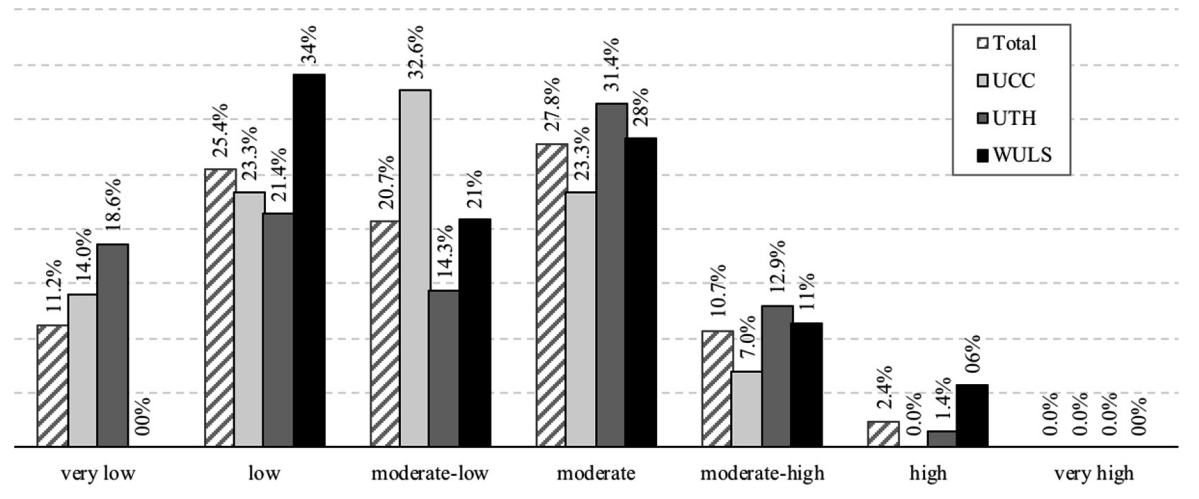

Fig. 8. Economic condition of respondents (income)

\subsection{Analysis}

On a scale of 1 (least positive) to 5 (highly positive), students were firstly asked to evaluate a number of qualities with reference to the UPS they use most, these are: their aesthetics, natural environment (greenery), safety, tranquillity, overall space quality (e.g. cleanness), the vigour of their social environment, whether they provide a sense of community and whether they have a unique or special character. Figure 9 presents the results (average scores) both for the total sample and for each specific case, making clear that UPS in all universities examined are in general of good quality (most quality scores are above 3 ). At a rather medium level to all UPS is tranquillity, perhaps due to the fact that these places are quite lively and busy urban spaces. In Greece, UPS seems to suffer from low quality natural environment (greenery), something that is typical to all cities in the country in general (Arvanitidis and Nasioka 2017). However, Greek students seems to be quite happy with the overall quality of space. 


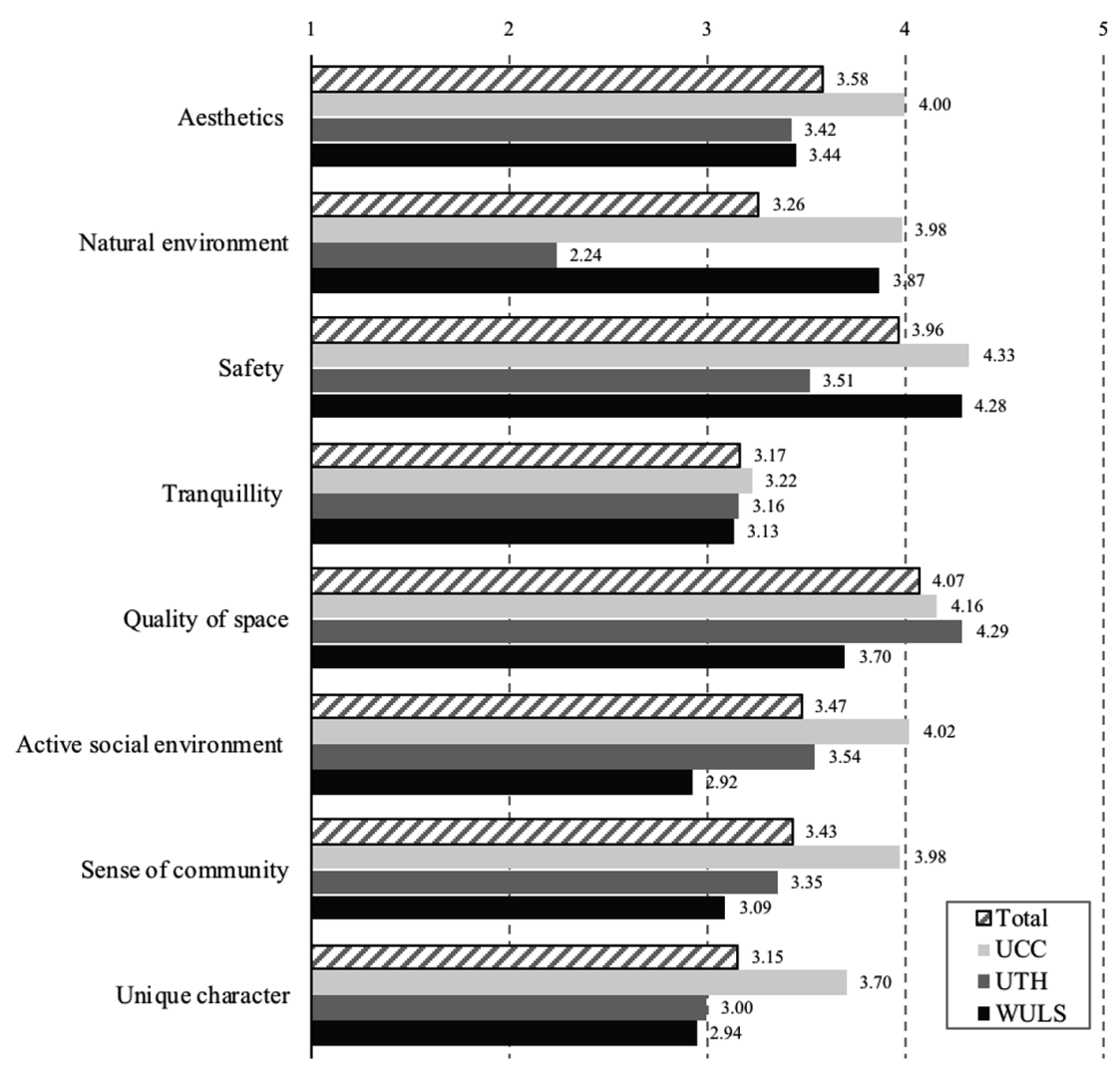

Fig. 9. Qualities of UPS

The next question examined the facilities that UPS offer. In particular, students were asked to assess (on a scale of 1 to 5) whether the UPS they use most provides quality facilities for visitors (e.g. toilets, parking, etc.), places to sit and work, internet facilities, places with interactive information, facilities for energy provision, facilities for recreation and commercial activities (e.g. refectory, vending machines), and maps. Figure 10 depicts the average scores acquired (both for the total sample and each case study). In general, we see that a low assessment of UPS in WULS is made in terms of adequate places to work and of spaces with interactive information, that latter of which is also the case in both UCC and UTH. Recreational facilities are of shortage in Volos' UPS. Internet provision facilities are valued quite highly in UCC but rather low in WULS. Overall, comparing the three case studies, it seems that the students of UCC are the most contented with the UPS of their university, something that can be attributed to the overall design of the university space. 


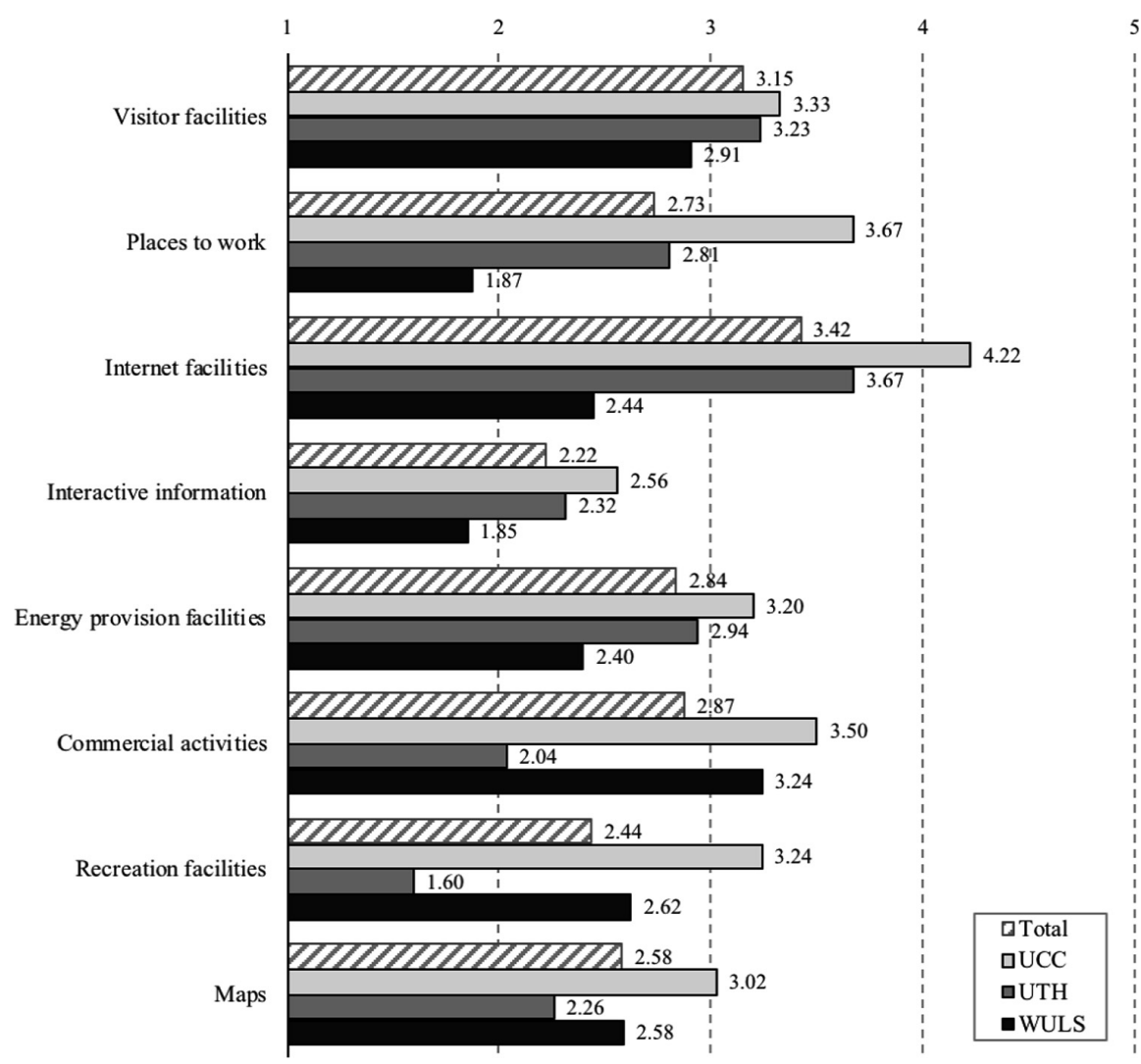

Fig. 10. Facilities of UPS

The following question attempted to gauge how content students are with UPS. We asked them to specify (on a scale of 1 to 5) whether the UPS they use most are appreciated by their peers, whether they think that UPS advance the quality of student life, the degree of their overall satisfaction they receive, and whether they believe that there are improvement that need to be made in UPS. Figure 11 illustrates the findings. As can be seen, all students are generally quite happy with the UPS they use (all average scores are above 3). As before, the most satisfied are the students in Cork. Students in Warsaw are happy too, but to a lesser degree, highlighting the need for UPS improvements. 


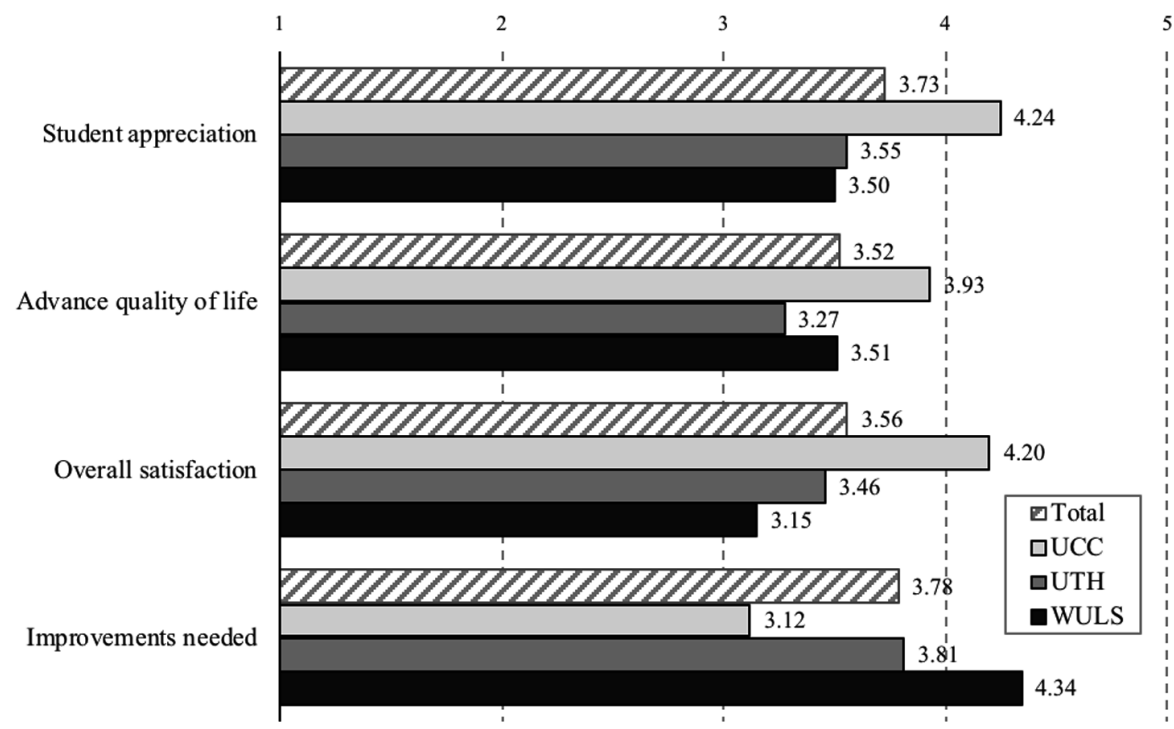

Fig. 11. Evaluation of UPS

A set of questions explored how students actually use the UPS. Firstly, we examined how often students visit the UPS they use most. Figure 12 portrays these patterns. We see that of the three cases under study, UCC students are those who visit UPS more intensively; the majority $(31.1 \%)$ use UPS multiple times a day. Polish and Greek students, in contrast, are less frequent users, the majority of which $(33.3 \%$ and $45.7 \%$, respectively) uses UPS more than three times a week (but not every day).

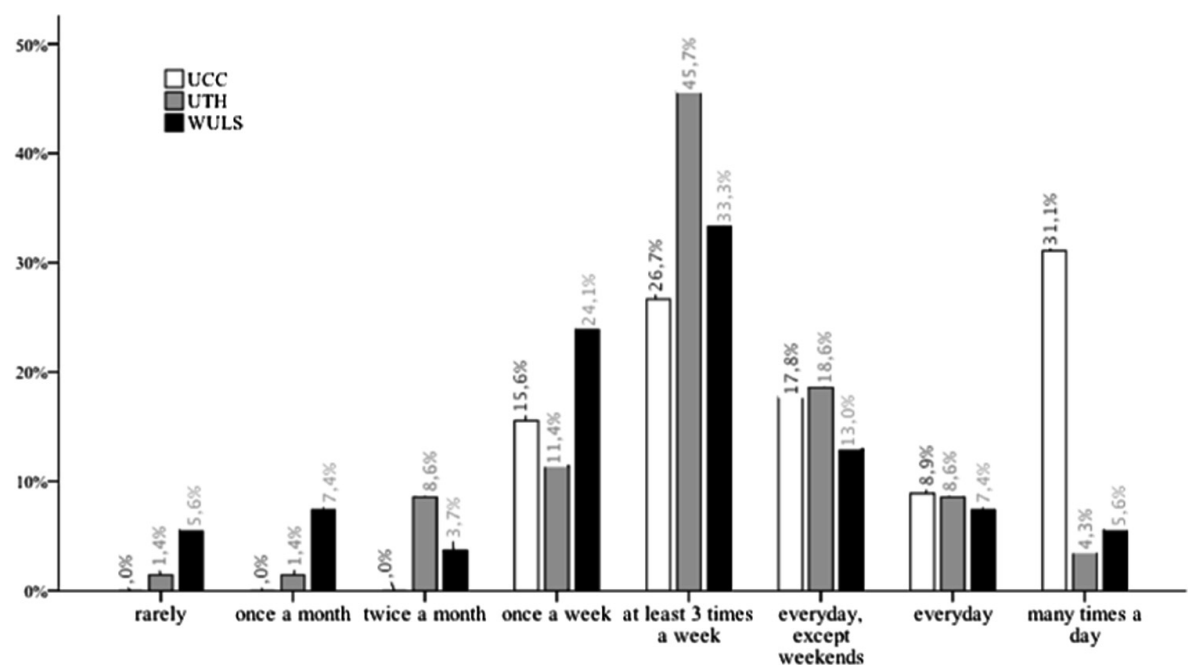

Fig. 12. Intensity of UPS use 
With regard to the activities undertaken when in UPS, as expected, most students go there to work/study and to socialize with their fellow students (Fig. 13). This for the Polish students is combined with drinking (coffees, soft drinks, etc.), eating (snacks, sandwiches, etc.), relaxing and strolling, whereas Greek students spend more time on

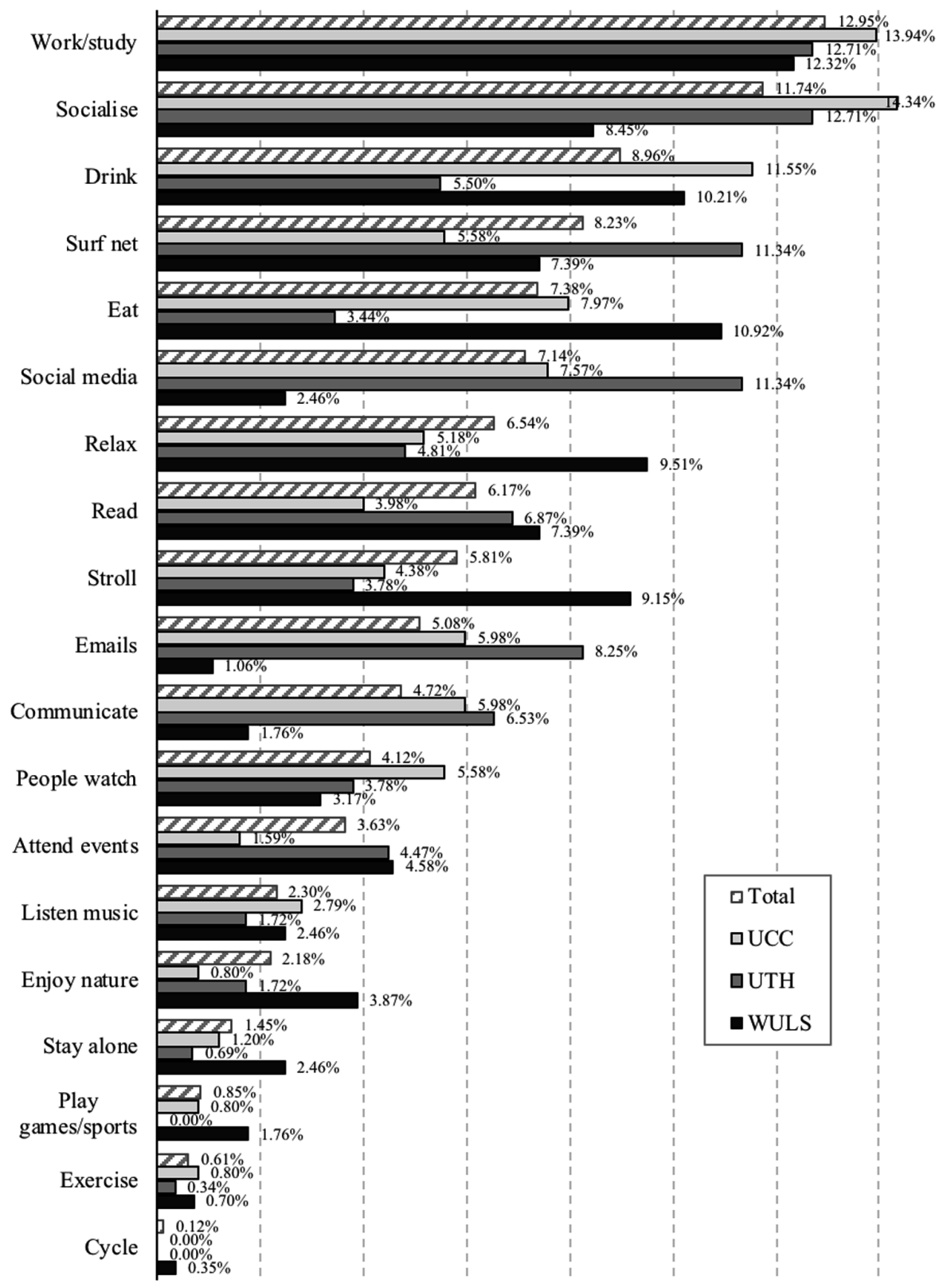

Fig. 13. Activities undertaken in UPS 
rather private activities, such as surfing the internet, catching up on social media and checking the emails. Interestingly, spending time alone is not a favourable option for all three student groups examined.

A number of subsequent questions explored how university students use ICTs, both in general and when they are in UPS. Figures 14 and 15 respectively present data on which personal devices respondents use and the intensity of their employment in the course of a single day, whereas Fig. 16 shows where people access the internet the most. As expected, smartphones, followed by laptops, are the devices used the most by all students; tablets are the least used technological devices. Desktop computers are not very popular in all cases examined, but students of UCC seems to use them at a higher degree as compared to students of UTH and WULS. Respondents access the internet mainly at home and on campus, both of which are places where students naturally spend most of their time. Irish and Polish students, as compared to Greeks, are more connected in every place (always connected), whereas Greeks seems to use the internet higher, compared to others, when they are at shops and retail outlets. As expected, all students use the internet in their daily life; since none of the respondents selected the option "I never use the internet".

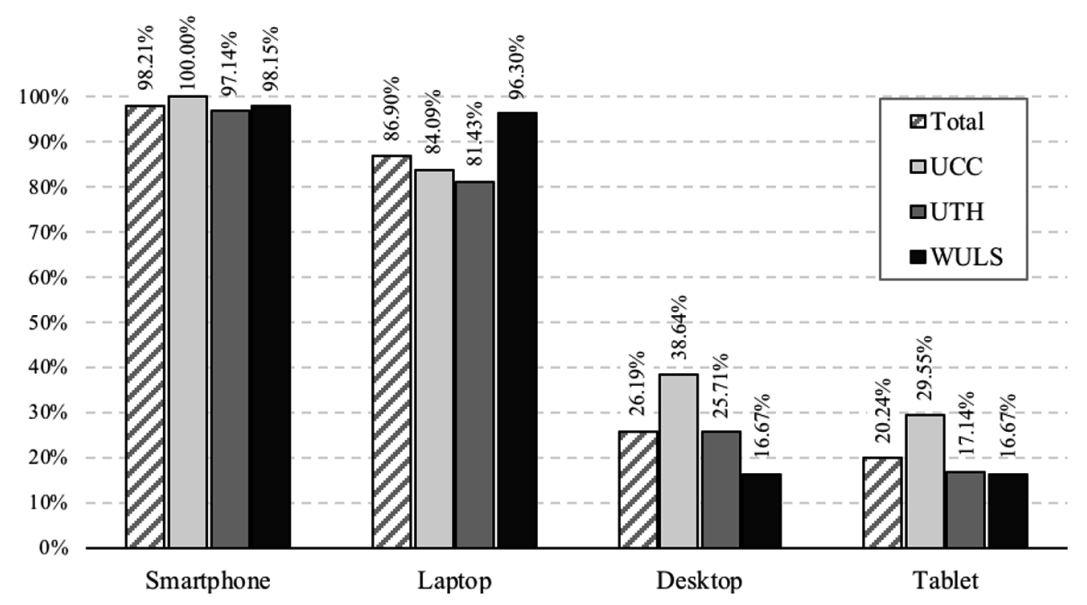

Fig. 14. ICTs used in everyday life 


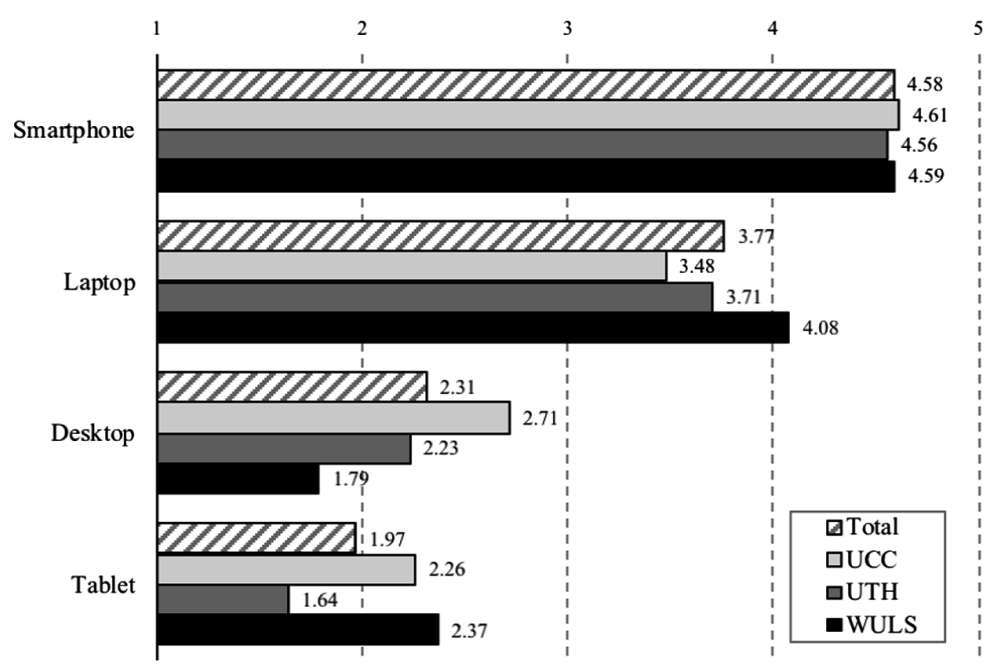

Fig. 15. Intensity of ICTs use in everyday life

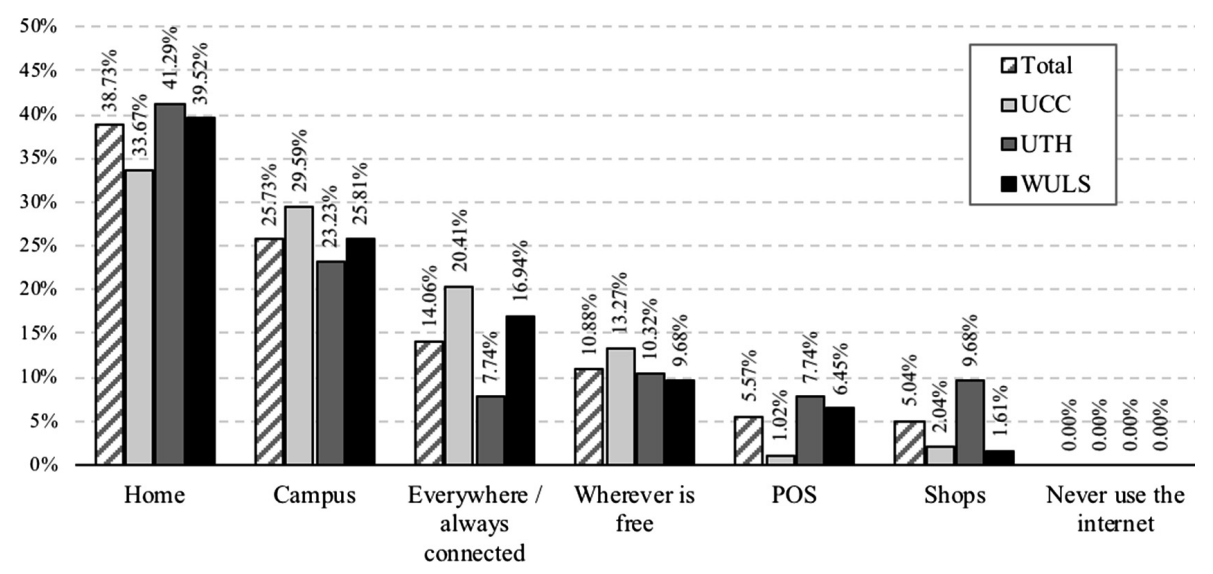

Fig. 16. Internet use in everyday life

Turning to technologies usage in UPS, Fig. 17 depicts how often personal mobile devices are used by the students. As before, smartphones are the principal instrument used, followed by laptops. Greeks, as compared to Irish and Polish students seem to use, at a lesser extent, both laptops and tables when they are in UPS. Polish students, in turn, use their tablets to a higher degree, in comparison to the other two groups. Internet use in UPS is quite popular (Fig. 18); the majority of UCC students are always connected $(53.5 \%)$, whereas both WULS and UTH students use it quite a lot $(50 \%$ and $38.6 \%$ of them respectively). Interestingly, of the three groups examined, Greek students seems to be those that use the internet the least when they are in UPS, as one out of three (that is about $30 \%$ ) reports that they use it only occasionally. 


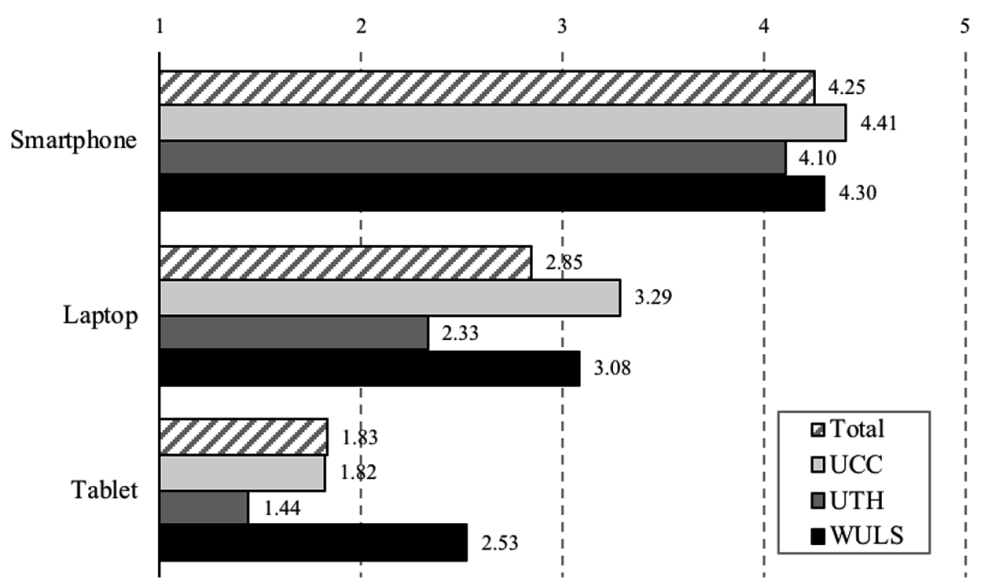

Fig. 17. Intensity of ICT use in UPS

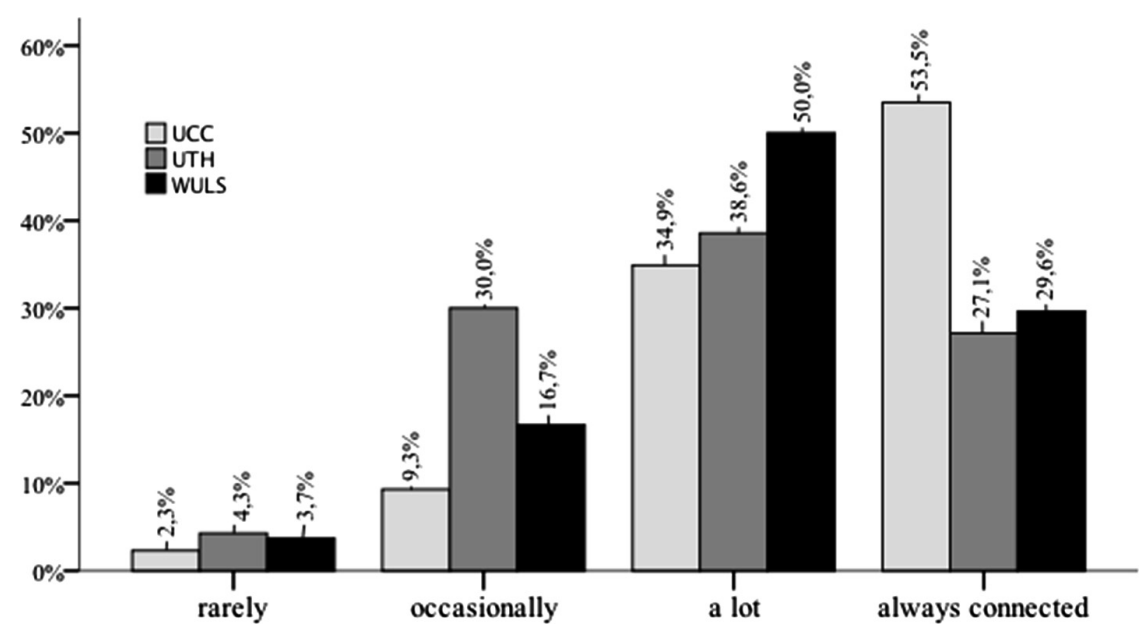

Fig. 18. Internet use in UPS

The questions that follow focus on management issues concerning UPS. First, we examine students' perceptions and attitudes towards ICTs and UPS and their maintenance (Figs. 19 and 20), then we move to assessments of stakeholders' capability to efficiently manage the UPS (Fig. 20), and finally we explore students' willingness to contribute to the provision, maintenance and improvement of the UPS by volunteering personal time (Figs. 22 and 23) or offering a small part of their income (Figs. 24 and 25).

To shed light on views and stances towards UPS and ICTs we asked students to evaluate (on a scale of 1: strongly disagree, to 5: strongly agree) the following statements: (1) UPS are absolutely essential to the university campus, (2) internet and Wi-Fi provision is absolutely essential to UPS, (3) students (i.e. users) should be heavily 
involved in UPS design, (4) students (users) should be heavily involved in UPS management, (5) security cameras should be applied in UPS, (6) controlled access should be applied in UPS, and (7) people should contribute financially to the creation and maintenance of UPS. As Fig. 19 reveals, all students believe that both UPS is necessary to the university campus and that Wi-Fi provision is essential to UPS. Turning to issues of user involvement in UPS design and management, students are rather neutral. In comparative terms, more prone to get involved are those of WULS and the least those of UTH. This might be related to the educational background of both; the former are studying (in majority) landscape architecture (so UPS design presents a challenge), whereas the latter are mainly students of economics. In regard to the issue of controlling access in UPS, students seem rather negative. Free UPS access for everybody is certainly what they prefer (though Greeks to a lesser degree), whereas students appear less negative (as compared to the controlled access) to the question of applying security cameras in UPS, with the Irish being more tolerant (in relation to Greeks and Polish) to such a development. Moving to the matter of financial contribution for the creation and maintenance of UPS, students are unanimously opposed to it.

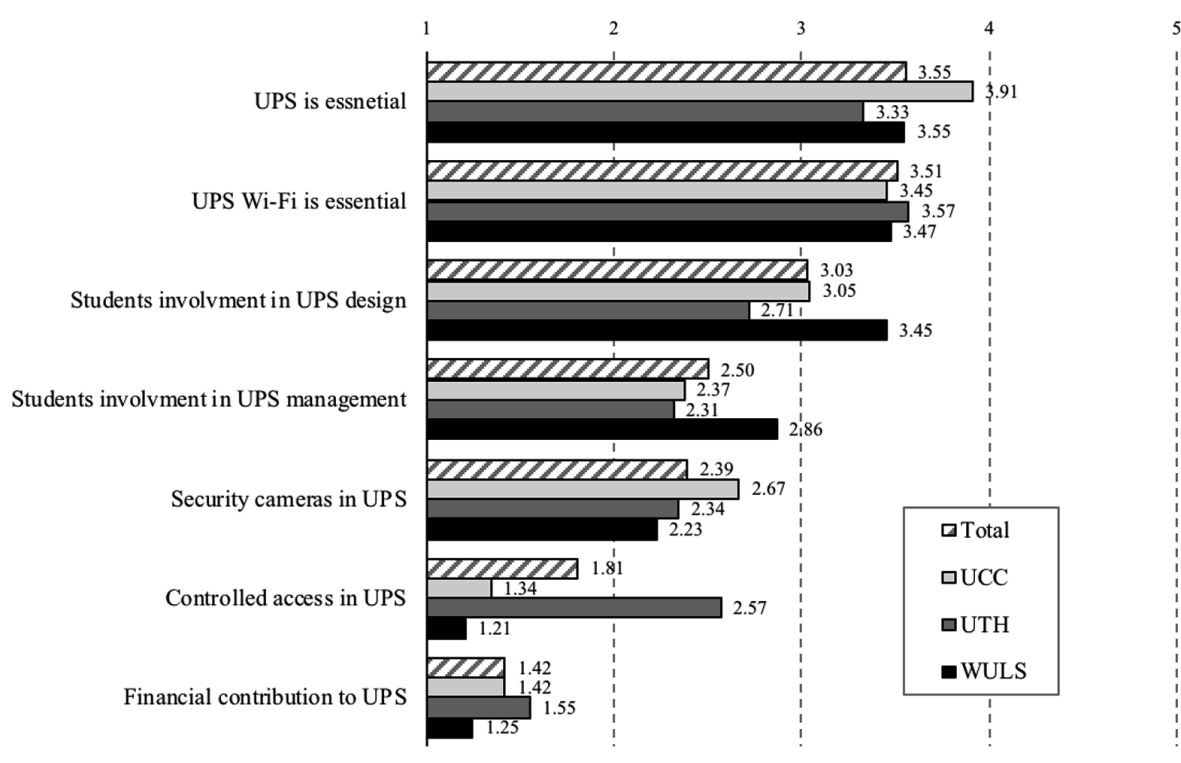

Fig. 19. Attitudes towards UPS and ICTs

This brings us to the question of who should pay for the costs of UPS. Figure 20 depicts the answers given by our sample. Clearly, the university is held responsible for the provision of this service and to a lesser degree the city and its administration; certainly such costs should be not born by the students. 


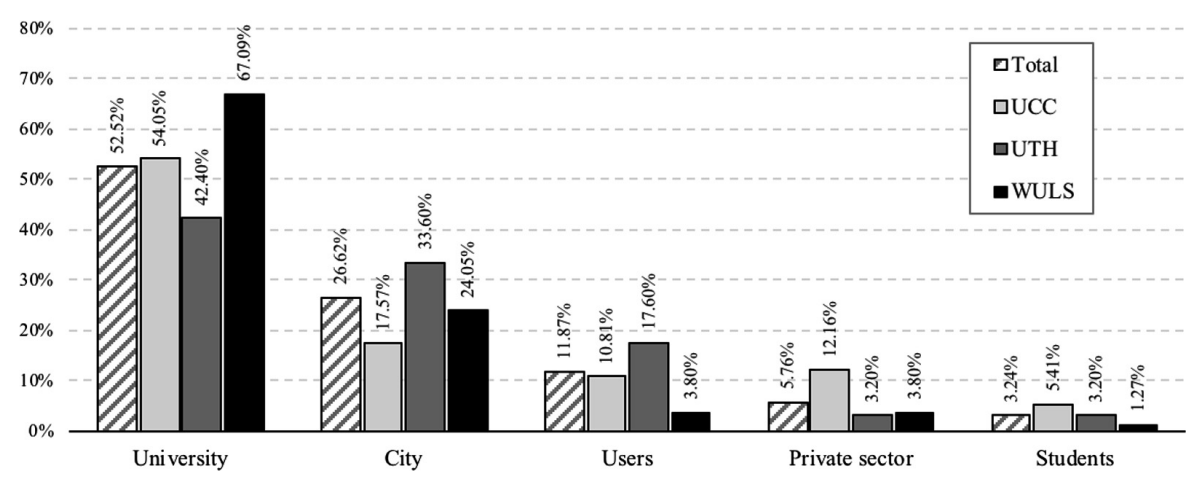

Fig. 20. Paying the costs of UPS

Moving to assessments of stakeholders' capacity to manage UPS, Fig. 21 shows that respondents believe that the university is the most capable of doing so. Provocatively, Polish students value very high student clubs and associations for their ability to perform the task (actually higher than the University). A special body created for this job is assessed relatively higher in Ireland, and the city authorities score relatively higher in Greece. Interestingly, the private sector scores last in all cases examined.

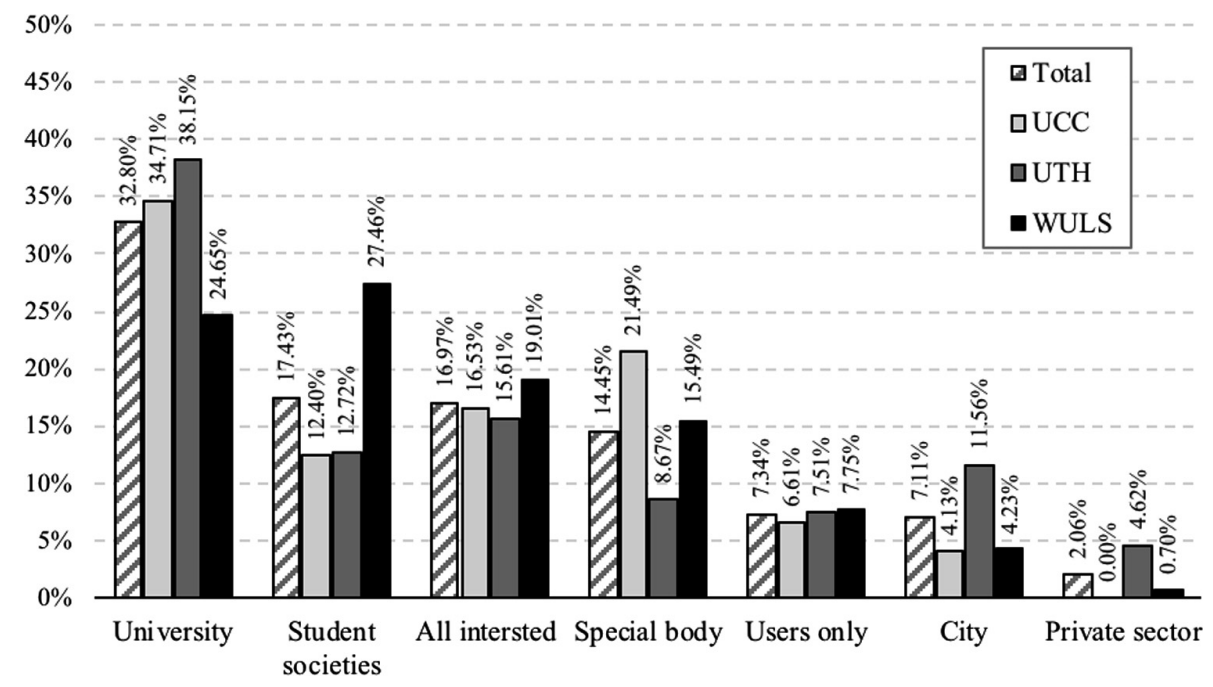

Fig. 21. Capability for UPS management 
Finally, we examine the willingness of students to contribute in the provision and maintenance of UPS, by either donating money or volunteering some of their spare time to help look after the resource. Figures 22 and 24, corroborating our previous findings, reveal that students are reserved (to a degree) to help look after UPS and rather unwilling to offer money towards their improvement and maintenance. Of those willing to contribute, Greeks seem a bit more keen (compared to others) on providing both time (on average $3.96 \mathrm{~h}$ ) and money for UPS management, and Polish are more reserved to both options (on average the hours that are willing to volunteer are 2.22).

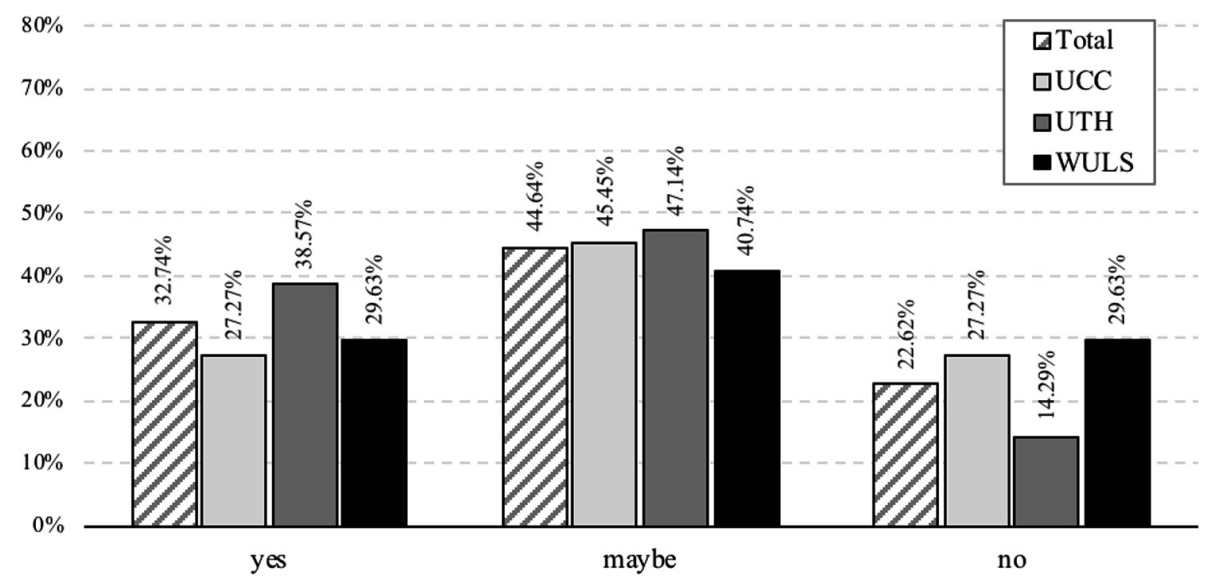

Fig. 22. Willingness to help look after UPS

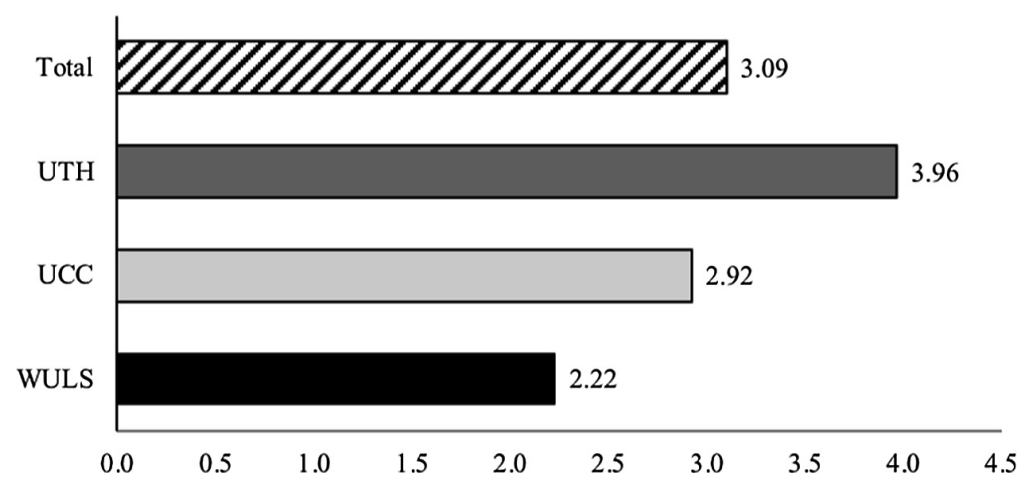

Fig. 23. Willingness to help look after UPS - hours volunteered 


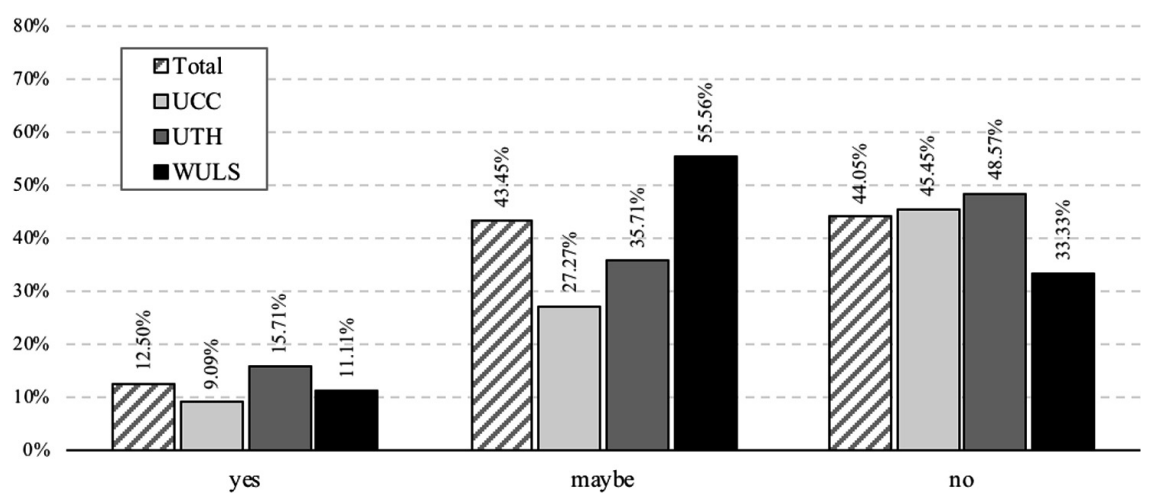

Fig. 24. Willingness to contribute financially for UPS
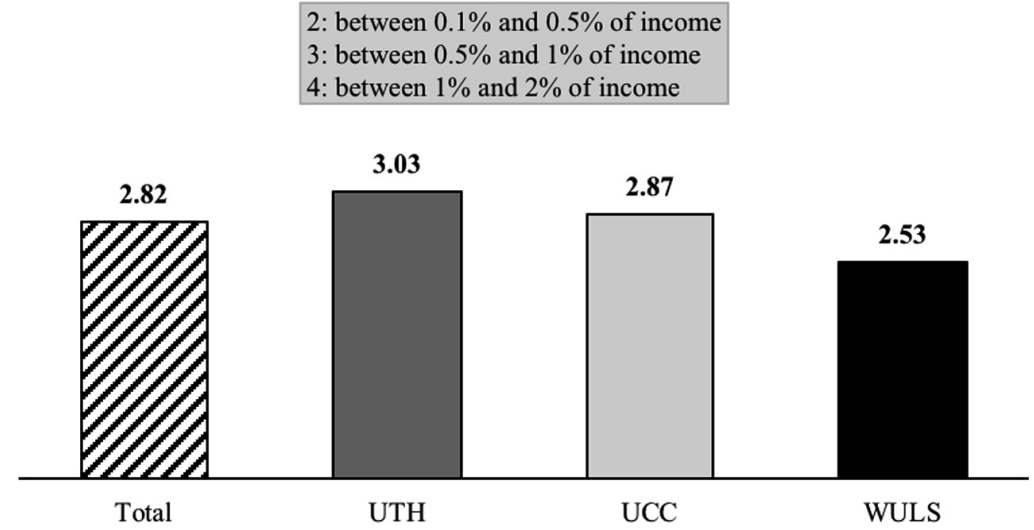

Fig. 25. Willingness to contribute financially to UPS - percentage of income offered

\section{Conclusions}

This chapter has explored how university students perceive and use UPS and ICTs in three cases across Europe: The University College Cork in Cork (Ireland), the University of Thessaly in Volos (Greece) and the Warsaw University of Life Sciences in Warsaw (Poland). Data were collected through an online questionnaire survey that explored students' self-reported views, attitudes, stances and behaviours towards UPS and ICTs, examining a number of issues, including the qualities of and facilities available in UPS, the frequency of UPS use and the activities performed, the kind of technological devices and services employed and the intensity of such usage, as well as student's willingness to participate in UPS maintenance and provision. This allows to identify practices of UPS usage and emerging patterns of engagement with people and space, along with preferable designs and ways of management. Moreover, the three 
case studies examined enable us to spot similarities and differences in the above trends, i.e. between North Europe (Ireland) vs. South Europe (Greece) vs. Central/East Europe (Poland), that should be attributed to culture and local socio-economic conditions and lifestyles.

The analysis we conducted, though preliminary and descriptive in nature, revealed a number of points which we highlight thereafter. First, mutatis mutandis, all universities examined provide good quality UPS, with adequate facilities, that advance contemporary student life. An issue perhaps exists in Warsaw, where students report problems with the internet facilities and a relative shortage of places to sit and work. Second, students appreciate the UPS available and use them quite a lot in their everyday life as places to meet, interact and collaborate with their fellow students, as well as spaces where, taking advantage of the Wi-Fi facilities available, they can resort to study and work, to search for information and to communicate with the rest of the world. As such UPS play a key role in strengthening students' interaction and socialisation and reinforcing their technological acquaintance and literacy. Third, smartphones constitute the principal ICTs device that students use, both outside university and when they are in UPS, satisfying their needs for wireless connection an an time and place. Fourth, despite the importance of good-quality 'wified' UPS in contemporary life, students seem rather reluctant to take part in their improvement and management, approaching it as a kind of public good which the University is obliged to provide at no (extra) cost to the user. This explains, in part, why they are also unwilling to accept measures of UPS surveillance and controlled access, which though they will increase security and protection of property and life, they would presumably jeopardise their freedom of expression and movement.

\section{References}

Arvanitidis, P., Nasioka, F.: Urban open greenspace as a commons: an exploratory case study in Greece. Öffentl. Sekt. 43(1), 19-32 (2017)

Aurigi, A., De Cindio, F.: Augmented Urban Spaces: Articulating the Physical and Electronic City. Ashgate, Aldershot (2008)

Boren, Z.D.: There are officially more mobile devices than people in the world. The Independent, Tuesday 7 October 2014. http://www.independent.co.uk/life-style/gadgets-and-tech/news/ there-are-officially-more-mobile-devices-than-people-in-the-world-9780518.html. Accessed 7 Oct 2015

Graham, S.: Bridging urban digital divides? Urban polarisation and information and communications technologies (ICTs). Urban Stud. 39(1), 33-56 (2002)

Griffith, J.C.: Open space preservation: an imperative for quality campus environments. J. High. Educ. 65(6), 645-669 (1994)

Gumprecht, B.: The campus as a public space in the American college town. J. Hist. Geogr. 33 (1), 72-103 (2007)

Hampton, K.N., Gupta, N.: Community and social interaction in the wireless city: wi-fi use in public and semi-public spaces. New Media Soc. 10(6), 831-850 (2008)

Hampton, K.N., Livio, O., Sessions, G.L.: The social life of wireless urban spaces: internet use, social networks, and the public realm. J. Commun. 60(4), 701-722 (2010) 
Hatuka, T., Toch, E.: The emergence of portable private-personal territory: smartphones, social conduct and public spaces. Urban Stud. (2014). https://doi.org/10.1177/0042098014524608

Leyshon, M., DiGiovanna, S., Holcomb, B.: Mobile technologies and youthful exploration: stimulus or inhibitor? Urban Stud. 50(3), 587-605 (2013)

McFarland, A.L., Waliczek, T.M., Zajicek, J.M.: The relationship between student use of campus green spaces and perceptions of quality of life. Hortic. Technol. 18(2), 196-319 (2008)

Speake, J., Edmondson, S., Nawaz, H.: Everyday encounters with nature: students' perceptions and use of university campus green spaces. Hum. Geogr. 7(1), 21-31 (2013)

Valentine, G.: Living with difference: reflections on geographies of encounter. Prog. Hum. Geogr. 32(3), 323-337 (2008)

Open Access This chapter is licensed under the terms of the Creative Commons Attribution 4.0 International License (http://creativecommons.org/licenses/by/4.0/), which permits use, sharing, adaptation, distribution and reproduction in any medium or format, as long as you give appropriate credit to the original author(s) and the source, provide a link to the Creative Commons license and indicate if changes were made.

The images or other third party material in this chapter are included in the chapter's Creative Commons license, unless indicated otherwise in a credit line to the material. If material is not included in the chapter's Creative Commons license and your intended use is not permitted by statutory regulation or exceeds the permitted use, you will need to obtain permission directly from the copyright holder. 